\title{
Study of Facial Dermatoses in Adult Patients in Tertiary Care Hospital
}

\section{IJCRR}

Section: Healthcare

Sci. Journal Impact

Factor: 6.1 (2018)

ICV: 90.90 (2018)

(c) (i) (8)

Copyright@IJCRR

\section{Palak Kedia ${ }^{1}$, Sugat Jawade ${ }^{2}$, Kavita Singh ${ }^{3}$}

Junior Resident, Department of Dermatology, Venereology \& Leprology, Jawaharlal Nehru Medical College, Datta Meghe Institute of Medical Sciences, Sawangi (Meghe), Wardha, (Maharashtra), India; 'Professor, Department of Dermatology, Venereology \& Leprology, Jawaharlal Nehru Medical College, Datta Meghe Institute of Medical Sciences, Sawangi (Meghe), Wardha, (Maharashtra), India; ${ }^{3}$ Professor, Computer Technology, Yeshwantrao Chavan College of Engineering, Nagpur, (Maharashtra), India

\section{ABSTRACT}

Background: Face is the most prominent part of the body. Every person is concerned about their physical appearance. Even a single lesion on the face can cause anxiety and can lead to poor self-image. As there is the paucity of comprehensive data on facial skin disorders, this study has been taken up to determine the frequency and clinical characteristics of the skin disorders predominantly affecting face.

Objectives: To study the prevalence \& clinical pattern of facial dermatoses in adult patients. Methods: The study will be done in the Department of Dermatology, JNMC and AVBRH, Sawangi, Wardha. 1045 patients of age 18 years and above will be included after taking informed consent. After considering the inclusion \& exclusion criteria, a record of patients with facial dermatoses will be maintained.

Results: The result would be undertaken by SPSS.

Conclusion: Conclusion will be based on the findings of the study.

Key Words: Facial dermatoses, Acne, Pigmentation, Melasma, Face

\section{INTRODUCTION}

Dermatoses refers to diseases of skin, nails and hair. The skin has various layers like epidermis, dermis and subcutaneous tissue. Any condition affecting the skin, any or all of its layers, could be referred to as dermatosis. If dermatosis occurs on the face, it is called as facial dermatosis. Prevalence of skin diseases in the general population varies from $7.86 \%$ to $11.16 \% .^{1}$ Many skin diseases like acne vulgaris, melasma, specifically affect the face and can be distressing to patients. ${ }^{2}$ Facial skin differs from the skin of other regions of the body. ${ }^{3,4}$ It is thinner, has a larger number of sebaceous glands, smaller hair follicles than in scalp which is larger in number than the skin in other areas of the body. The richness of blood supply to facial skin and nearness of the superficial vascular plexuses to the skin surface and the ready dilatation of its blood vessels ensures that all inflammatory dermatoses affecting the face rapidly cause a deep erythema. ${ }^{3}$ Thus, it is important to know the various facial dermatoses and their clinical features.
Causes of facial dermatoses include infectious and non-infectious diseases. Infections like Impetigo, Tinea Faciei, Tinea Barbae, Herpes Simplex, Molluscum Contagiosum can occur on the face. Non-infectious disorders of the face could be due to a variety of reasons like pigmentary disorders, acne, autoimmune diseases, photodermatitis, allergic or irritant contact dermatitis, metabolic disorders.

\section{RATIONALE}

The face is aesthetically the most prominent part of the body. Every person is concerned about their physical appearance which helps them to present themselves confidently. Even a single lesion on the face can cause anxiety and if present for long periods, it can cause reactive depression and can lead to poor self-image. ${ }^{3}$ Facial dermatoses can be stressful as they are easily visible. ${ }^{5,6}$ Therefore, it is important for early identification and treatment of facial skin disorders.

\section{Corresponding Author:}

Dr. Palak Kedia, Junior Resident, Department of Dermatology, Venereology \& Leprology, Jawaharlal Nehru Medical College, DMIMS, Sawangi (Meghe), Wardha, (Maharashtra), India; Contact: 9930131883; E-mail: palakk13@gmail.com

ISSN: 2231-2196 (Print)

Received: 10.09 .2020
ISSN: 0975-5241 (Online)

Revised: 17.10 .2020
Accepted: 11.11 .2020 
Previous studies have focused mostly on specific diseases of facial dermatoses. However, there is a paucity of comprehensive data on facial skin disorders. Hence, this study has been taken up to determine frequency and clinical characteristics of the skin disorders predominantly affecting face which can add newer knowledge in this field. The information gathered could then be used to develop or improve clinical and medical research, as well as improve preventive healthcare.

\section{OBJECTIVES}

To study prevalence and clinical pattern of Facial Dermatoses in adult patients attending Dermatology OPD in a Tertiary Care Hospital. We will study the prevalence of facial dermatoses in adult patients and the clinical pattern of facial dermatoses adult patients.

\section{MATERIALS \& METHODS}

Study design: Prospective, Cross-sectional Hospital-based study.

Sample size: This is a new study and prevalence of facial dermatosis in adult patients is not known. Considering the total number of patients attending the Dermatology OPD in AVBRH in 1 year (average being 50,000) with a margin of error $3 \%$ and confidence interval of $95 \%$, the sample size calculated by using OpenEpi software is 1045 for the present study.

\begin{tabular}{ll}
\multicolumn{2}{l}{ Sample Size( $\boldsymbol{n}$ ) for Various Confidence Levels } \\
Confidence Level(\%) & Sample Size \\
$95 \%$ & 1045 \\
$80 \%$ & 453 \\
$90 \%$ & 741 \\
$97 \%$ & 1275 \\
$99 \%$ & 1778 \\
$99.9 \%$ & 2838 \\
$99.99 \%$ & 3880
\end{tabular}

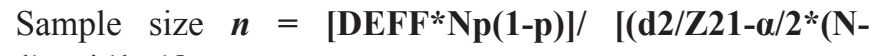
1) + p*(1-p)]

Results from OpenEpi, Version 3.

\section{Study population}

1045 patients of both genders, with age 18 years and above, who have complaints of facial dermatoses, attending Dermatology OPD in AVBRH, Sawangi.

\section{Study setting}

Patients suffering from Facial Dermatoses with age 18 years and above, attending the Out-Patient Department of Dermatology, AVBRH, Sawangi, Wardha from September 2018 to August 2020

Stusy period: September 2018 to August 2020.

\section{Inclusion criteria:}

1) Patients willing to give informed consent and participate in the study.

2) Clinically diagnosed patients of facial dermatoses, with age 18years20 and above, irrespective of gender.

3) Patients with the facial presentation of generalized dermatological disorders.

\section{Exclusion criteria:}

1) Patients with age $<18$ year

2) Patients with skin disorders but not involving the face.

3) Patients with lesions due to trauma on the face.

4) Patients with sole involvement of mucosa of oral cavity, lips or conjunctiva.

\section{Procedure}

Patients of facial dermatoses, with age 18 years and above, who will be attending the Out Patient Department of Dermatology, AVBRH, Sawangi, Wardha, will be enrolled after considering inclusion and exclusion criteria between September 2018 \& August 2020. Institutional Ethics Committee's permission will be taken. Written informed consent will be taken from all patients for voluntary participation and clinical photographs. Detailed history regarding age, sex, educational status, occupation, family history, past history, history of recurrence, systemic and topical drug history, procedures done on face will be taken. Detailed clinical cutaneous examination will be done for face and other body parts and if needed, skin biopsy and other investigations will be done.

\section{Data Analysis}

Statistical analysis will be done using SPSS software 17.0 version \& Graph Pad Prism 6.0 version

\section{EXPECTED RESULTS}

This study will generate statistical data about various facial dermatoses in adult patients in current scenario as there is paucity of literature in this aspect.

Various types of skin disorders involving the face, their prevalence over the face, most common age group and gender involved will be identified. 


\section{DISCUSSION}

Skin lesions affecting face are together called as facial dermatoses. So far only a few studies have been done on facial dermatoses with limited sample size. Jain et al did a study on 150 patients with facial dermatoses and found that $26.7 \%$ of them had pigmentary disorders with melasma being most common. ${ }^{7}$ Second leading etiology in $16.7 \%$ cases was acne. Other dermatoses included cyst, eczema and naevi. Agewise, $30.67 \%$ of facial dermatoses presented in the 3rd decade of life. Female preponderance with a female to male ratio 1.2:1 was observed. ${ }^{7}$ Gupta et al studied 300 male patients diagnosed with facial hyper melanosis. ${ }^{8}$ They found $40.3 \%$ of cases were between 31 and 50 years of age. Melasma affected $76.7 \%$ of the cases. Other dermatoses found were hyper melanosis around the orbit in $10.7 \%$, lentigines and freckles in $8.7 \%$, and acanthosis nigricans in $4 \%$ of the cases. ${ }^{8}$ Other studies related to this study in this hospital were reviewed..$^{9-11}$ Various dermatological problems are also reported. ${ }^{12,13}$

\section{CONCLUSION}

Conclusion will be based on the findings of the study.

\section{ACKNOWLEDGMENT}

Authors acknowledge the immense help received from the scholars whose articles are cited and included in references to this manuscript. The authors are also grateful to authors / editors / publishers of all those articles, journals, and books from which the literature for this article has been reviewed and discussed.

\section{Conflict of Interest: Nil}

Source of Funding: Nil

\section{REFERENCES}

1. Rao GS, Kumar SS. Pattern of skin diseases in an Indian village. Ind J Med Sci 2003;57(3):108.

2. Georgieva F. Facial Dermatoses: The Influence Of Expectations - Quality Of Life Before And After Treatment. Ind J Appl Res 2018; 8(4):3.

3. Marks R. Facial skin disorders. CRC Press; Jan. 2007.

4. Tagami H. Location-related differences in structure and function of the stratum corneum with special emphasis on those of the facial skin. Int J Cosm Sci 2008;30(6):413-34.

5. Tan AU, Schlosser BJ, Paller AS. A review of diagnosis and treatment of acne in adult female patients. Int J Women's Dermatol 2018;4(2):56-71.

6. Magin P, Adams J, Heading G, Pond D, Smith W. Psychological sequelae of acne vulgaris: results of a qualitative study. Canadian Family Physician 2006;52(8):978-9.

7. Jain M, Singh K, Kanodia S, Vishwender B. Clinico- epidemiology of facial dermatoses. Indian J Basic Applied Med Res 2018;7(2):154-8.

8. Gupta M, Mahajan VK. Clinical profile of 300 men with facial hypermelanosis. Journal of dermatological case reports. 2017 Dec 1;11(2):20.

9. Saoji V, Madke B. Use of low-dose oral warfarin in three cases of livedoid vasculopathy. Indian J Dermatol 2017;62(5):508.

10. Shivakumar KM, Kadashetti V, Chaudhary M, Patil S, Gawande M, Hande A. Prevalence of Oral Mucosal Lesions in Patients with Dermatological Diseases Attending Tertiary Care Hospital in Central India. J Krishna Inst Med Sci 2017;6(3).

11. Henry D, Singh A, Madke B, Kedia P. A case of the altered clinical picture of extensive tinea corporis (tinea as a great mimicker). Iranian J Dermatol 2019;22(3):107-9.

12. Sahu PJ, Singh AL, Kulkarni S, Madke B, Saoji V, Jawade S. Study of oral tranexamic acid, topical tranexamic acid, and modified Kligman's regimen in the treatment of melasma. J Cosme Dermatol 2020;19(6):1456-62.

13. Verma SB, Madke B, Joshi RS, Wollina U. Pseudoedematous Striae- An Undescribed Entity. Dermatol Therapy 2020:e13754. 